\title{
FAMILY-CENTRED PRACTICE IN A REHABILITATION SETTING
}

\author{
Raveena Victor John and Mary Butler
}

\section{INTRODUCTION}

In this paper we explore the importance of integrating whānau (family) into all aspects of the rehabilitation process in a New Zealand context. An individualistic model of healthcare practice leads to significant challenges in ensuring that this is a seamless process and there can be real hurdles to enabling partnership and collaboration between healthcare practitioners, clients, and their whānau. The paper is written as a reflection of the experience of the first author, who came to understand that the issues arising on her fieldwork placement had parallels with her own personal experience. She was supported and encouraged in her reflections by the second author who has previously published about the importance of family-centred care (Butler, 20 I0, 20 II; Barrett, Hale \& Butler, 20 I3; Barrett, Butler \& Hale, 2016).

The issue arose during a fieldwork placement in a rural setting. The first author, an international student, was struck by the importance of whānau in ensuring good rehabilitation outcomes for an elderly Māori gentleman. The situation particularly resonated with her because of her personal history of the rehabilitation process when her own mother had a stroke. An occupational therapist was instrumental at that time in using creative ways of integrating the family fully into the rehabilitation process with her mother, who eventually made an excellent recovery. This positive experience was instrumental in the decision of the first author to become an occupational therapist. It made her particularly sensitive to the importance of ensuring that she learns to practice in familycentred ways.

\section{FAMILY-CENTRED PRACTICE WITH OLDER ADULTS}

Family-centred practice within the healthcare setting has an important role to play in tackling a rapidly increasing population of older adults (Anderson \& Rose, 2019). Person- and family-centred care (PFCC) involves four key aspects: (i) dignity and respect; (ii) participation; (iii) information sharing; and (iv) collaboration (Giosa, Holyoke, \& Stolee, 2019). A systematic review by Giosa et al. (2019) described how each healthcare discipline is guided by a distinctive model where it addresses one or more key concept of the PFCC in which it can be similar or different to another discipline.

Shared decision-making, partnership, trust, and respect are key components of collaboration (McGill University, 2020). For instance, occupational therapists focus more on clients' participation in activities of daily living, while other healthcare professionals focus of other elements of care. This makes collaborative work important (Giosa et al., 2019). The importance of collaboration for occupational therapists is reflected in the competencies for registration, which include building partnerships and working collaboratively with healthcare professional, clients and their whānau. (OTBNZ, 20I5b). 
Most older adults prefer the involvement of their families in at least one aspect of their care (for example, decisionmaking) (Lao, Low, \& Wong, 2019; Aschbrenner et al., 2014; Morton, Tong, Howard, Snelling, \& Webster, 20I0). Family involvement provides a sense of support, comfort and understanding (Ekberg, Meyer, Scarinci, Grenness, \& Hickson, 2015). However, there are studies that point out the lack of opportunities afforded to families to participate in the client's care (Ekberg et al., 2015; Hardin, 2012).

Some of the preferences for family-centred care are associated with socioeconomic status and culture (Chang \& Yu, 2013; Anderson \& Rose, 2019). In New Zealand, there are strong suggestions that Māori clients particularly value family-centred care (Martin, 2018). The principles of the Treaty of Waitangi include: (a) partnership (b) participation; and (c) protection (MHNZ, 2014), which are reflected in the development of the culturally relevant whānau ora (family health) approach (MHNZ, 20I8). The principles are often expressed in terms of particular values. For example, whakarangatira (enrich), awhi (support), kotahitanga (togetherness) and aroha (compassion). In New Zealand there are particular issues in accessing any healthcare for some rural communities and the distance involved often compound the difficulties for ensuring family-centred care (Chan, Hart, \& Goodman, 2007).

\section{ENCOUNTERING THE NEED FOR FAMILY-CENTRED PRACTICE}

The first author worked with a Māori client named Hoani (pseudonym) at the rehabilitation unit during breakfast group. Hoani had multiple fractures on the dominant side of his body due to a fall. It included fractures to the neck of femur, humeral head, and distal radius. Prior to the fall, he lived independently. Due to the fall, he could not safely and independently engage in Activities of Daily Living (ADLs) such as self-care. He was deeply unhappy during rehabilitation sessions, complaining about wanting to go home and refusing to engage in activities such as a breakfast club. He refused all social interactions and often presented with a low mood. However, there was a shift in mood when his mokopuna (grandchild) visited him in the hospital during the school holiday which was on a weekday. He arrived smiling and introduced his mokopuna to the rest of the clients that were present at the breakfast group, insisting on making a cup of hot chocolate and enthusiastically taking part in the group. It was so obvious that this was what motivated him. This presented an ethical conundrum, because nothing in the hospital seemed to be set up to enable this kind of family-centred practice. When there was a discussion with Hoani, his daughter and mokopuna, they all said that Hoani needed more opportunities for the involvement of his mokopuna during his therapy sessions. However, this seemed impossible as occupational therapy working hours were during the weekdays from 8 a.m. to 4 p.m. which was not in line with the free times of his mokopuna as it clashed with school. Another factor in this case was that Hoani and his whānau lived in a rural area, and visiting required drives of almost two hours in both directions.

\section{FAMILY-CENTRED PRACTICE AS AN ETHICAL ISSUE}

The quadripartite ethical tool (QET) is a framework that encompasses four ethical schools: deontology, utilitarianism, virtue ethics and axiology (Drolet \& Hudon, 2015). Together, these can provide a lens to examine the issues faced by Hoani.

Deontology highlights the issue of autonomy and Hoani's actions clearly suggest that his autonomous wish was to work more closely with his family. Utilitarianism is all about the greatest good for the greatest number, and so therefore it may be argued that the narrow individualist interpretation of patient needs is actually cost efficient. Virtue ethics can provide a way of thinking about whether care and courage are virtues that the therapist might want to foster in order to meet the expressed need for family centred care. Finally, axiological ontology frames the specific values of the occupational therapist as centred on occupation. In this case, it was clear that Hoani was only going to participate in activities if his whānau was part of these. 
It is also important to consider exactly where the practitioner is situated in such decision-making. The first author comes from a culture where family values are important and it felt important for her to integrate this understanding into her practice, although she was nervous about doing so. As a foreign student in New Zealand she was aware that she found it difficult to have the confidence to express her opinions, especially where this seemed to be an issue of values and. She was unsure at times whether her views were in line with the values of the New Zealand culture and these effects on her behaviour are reflected in a study by Nayar and Sterling (2013) about transitioning from one country to another. However, a trip to a marae helped considerably with gaining clarity, when she heard several Mäori give speeches about how much they valued collaboration and whänau involvement in the healthcare system.

There are obvious environmental issues implicit in this case, not least the fact that occupational therapists were employed in a 9-5 employment contract. There were many ways that this might be addressed, but it would require high level agreement. And of course, Hoani was distanced from his whänau because of the rurality of their situation. There was very little point in suggesting to Hoani that he should Zoom his mokopuna, when it was the physical touch that he was missing.

\section{CONCLUSION}

It is clear, there are many things that need to be changed in order to enable family-centred practice in a rehabilitation setting. These changes will require adherence to the values and principles underpinning whānau ora care at all levels, from leadership to practitioners. The need for whānau to be involved was acutely obvious in the case of Hoani. The experience of the first author with her mother when she had a stroke and was involved in her care as a teenager was an excellent example of how good practice can be enabled. Her capacity to understand the human need for family-centred care gave her insights that she was able to apply to the New Zealand context and which will continue to shape her practice into the future.

Raveena Victor John is a Bachelor of Occupational Therapy student from Malaysia who is completing her final year of study at Otago Polytechnic, Dunedin, New Zealand. She is very passionate and enjoys supporting people to lead meaningful lives.

Mary Butler (10000-0003-3365-8995) is a Professor at Otago Polytechnic, Dunedin, New Zealand and teaches on both the undergraduate and postgraduate programmes at the School of Occupational Therapy. She is committed to supporting students to publish their work and this paper is an example of one such collaboration.

Correspondence to: E-mail: RAVE3@student.op.ac.nz

\section{REFERENCES}

Anderson, J. G., \& Rose, K. M. (2019). Family-focused care of older adults: Contemporary issues and challenges. Journal of Family Nursing, 25(4), 499-505. https://doi-org.op.idm.oclc.org/I0.1/77//0748407/9885337

Aschbrenner, K. A., Pepin, R., Mueser, K. T., Naslund, J. A., Rolin, S. A., Faber, M. J., \& Bartels, S. J. (2014). A mixed methods exploration of family involvement in medical care for older adults with serious mental illness. The International Journal of Psychiatry in Medicine, 48(2), 121-133. https://doi.org/10.2190/PM.48.2.e

Butler, M. (2010). Care ethics and the payment of family carers: implications for occupational therapy. World Federation of Occupational Therapy Bulletin, 62(November), 46-52. 
Butler, M. (20II). "Being, doing and belonging after brain injury: an ethnographic exploration of the capabilities approach." Sites: A Journal of Anthropology and Cultural Studies 8(2): 57-76.

Barrett, P., Butler, M., \& Hale, B. (2016). Ethical issues in family care today. Annual review of nursing research, (Ed) Susanne Gibbons, Springer.

Barrett, P., Hale, B., \& Butler, M. (2013). Family care and social capital: Voices of Informal Carers. Springer

Chan, L., Hart, G., \& Goodman, D. C. (2007). Geographic access to health care for rural medicare beneficiaries. The Journal of Rural Health, 22(2), 140-146. https://doi.org/I0.1III/j.1748-0361.2006.00022.x

Chang, S. H. \& Yu, C. L. (2013). Perspective of family caregivers on self-care independence among older people living in longterm care facilities: A qualitative study. International Journal of Nursing Studies, 50(5), 657-663. https://doi-org.op.idm.oclc. org/10.1016/j.ijnurstu.2012.10.013

Drolet, M. J. \& Hudon, A. (2015). Theoretical frameworks used to discuss ethical issues in private physiotherapy practice and proposal of a new ethical tool. Medicine, Health Care \& Philosophy, I8(I), 51-62. https://doi-org.op.idm.oclc.org/l0.1007/ sllol9-0|4-9576-7

Duncan, E. A. S. (20I I). Foundations for practice in occupational therapy (5th ed.). Scotland, United Kingdom: Elsevier Health Sciences.

Ekberg, K., Meyer, C., Scarinci, N., Grenness, C., \& Hickson, L. (20I5). Family member involvement in audiology appointments with older people with hearing impairment. International Journal of Audiology, 54(2), 70-76. https://doi-org.op.idm.oclc.org/ 10.3109/14992027.2014.948218

Giosa, J. L., Holyoke, P., \& Stolee, P. (2019). Let's get real about person- and family centered geriatric home care: A Realist Synthesis. Canadian Journal on Aging, 38(4), 449-467. https://doi.org/10.1017/507/4980819000023

Hardin, S. R. (2012). Geriatrics. Engaging families to participate in care of older critical care patients. Critical Care Nurse, 32(3), 35-40. https://doi-org.op.idm.oclc.org//0.4037/ccn2012407

Hart, J. L., Turnbull, A. E., Oppenheim, I. M., \& Courtright, K. R. (2020). Family-centered care during the COVID-19 era. Journal of Pain and Symptom Management, I-5. https://www.sciencedirect.com/science/article/pii/S0885392420302086

Lao, S. S. W., Low, L. P. L., \& Wong, K. K. Y. (2019). Older residents' perceptions of family involvement in residential care. International Journal of Qualitative Studies on Health \& Well-Being, 14(I), I-12. https://doi-org.op.idm.oclc.org//0.1080/I748 2631.2019 .161129

Martin, H. (2018, August 12). Māori and Pasifika families face discrimination, lack of support in health system - research. Stuff. Retrieved from https://www.stuff.co.nz/national/health//06067255/mori-and-pacific-families-face-discrimination-lack-ofsupport-in-health-system--research

McGill University. (2020). Canadian interprofessional health collaborative (CIHC) framework. https://www.mcgill.ca/ipeoffice/ipecurriculum/cihc-framework

Ministry of Health New Zealand. (2014, June 06). Treaty of Waitangi principles. Retrieved from https://www.health.govt.nz/ourwork/populations/maori-health/he-korowai-oranga/strengthening-he-korowai-oranga/treaty-waitangi-principles

Ministry of Health New Zealand. (2018, August 16). Whānau Ora programme. Retrieved from https://www.health.govt.nz/ourwork/populations/maori-health/whanau-ora-programme

Morton R. L., Tong A., Howard K., Snelling P., \& Webster A. C. (20l0). The views of patients and carers in treatment decision making for chronic kidney disease: Systematic review and thematic synthesis of qualitative studies. BMJ: British Medical Journal (Overseas \& Retired Doctors Edition), 340(7742), cl I2. https://doi-org.op.idm.oclc.org/dx.doi.org/bmj.cl I2

Nayar, S., \& Sterling, K. (2013). Occupational Strategies for Settling in New Zealand: Learning from Indian Immigrant Men. Journal of Occupational Science, 20(I), 62-72. https://doi.org/I0.1080/I4427591.2012.736343

Occupational Therapy Board of New Zealand. (2015a). Code of Ethics for Occupational Therapists. Wellington, New Zealand: Author. Retrieved from https://www.otboard.org.nz/wp-content/uploads/2015/04/CodeofEthics_April20I5-I.pdf

Occupational Therapy Board of New Zealand. (2015b). Competencies for Registration and Continuing Practice. Wellington, New Zealand: Author. Retrieved from https://www.otboard.org.nz/wp-content/uploads/20I5/04/Competencies_April20I5I.pdf

Statistics NZ. (n.d.). Gisborne region. Retrieved from https://www.stats.govt.nz/tools/20l8-census-place-summaries/gisborneregion

Swisher L. L., Arslanian L. E., \& Davis, C. M. (2005). The Realm-Individual-Process-Situation (RIPS) Model of Ethical DecisionMaking. HPA Resource, 5(3), I-8. http://www.capteonline.org/uploadedFiles/APTAorg/Practice_and_Patient_Care/Ethics/ Tools/RIPS_DecisionMaking.pdf 